\title{
Antibacterial Activity of the Organic Extracts of Stem Bark of Cinnamomum aromaticum Nees
}

\author{
Md. Anarul Hoque ${ }^{1}$, Mst. Afroza Khatun ${ }^{1}$, Rezuanul Islam ${ }^{1}$, Hossain Uddin \\ Shekhar ${ }^{2}$, Md. Enamul Haque ${ }^{2}$ and A. K. M. Mahbub Hasan ${ }^{2}$ \\ ${ }^{1}$ Department of Biotechnology and Genetic Engineering, Islamic University, Kushtia 7003, Bangladesh \\ ${ }^{2}$ Department of Biochemistry and Molecular Biology, University of Dhaka, Dhaka 1000, Bangladesh
}

Received: November 24, 2013; Accepted: May 19, 2014; Published (web): October 13, 2014

The stem bark of Cinnamomum aromaticum was sequentially extracted with chloroform, ethyl acetate and methanol. The extracts were evaluated for their antimicrobial property against five food-borne pathogenic bacteria namely Bacillus subtilis, Sarcina lutea, Xanthomonas campestris, Escherichia coli, and Klebsiella pneumonia. The results indicated that the pattern of inhibition against the microorganism depends largely upon the organic solvent used for extraction. Almost all the extracts showed variable degree of zone of inhibition against different bacterial species except the chloroform extract, which was found to be completely inactive. The zone of inhibition was 7-26 $\mathrm{mm}$ and 7-18 $\mathrm{mm}$ when the plant materials were extracted with methanol and ethyl acetate, respectively. The present study showed the presence of potential antibacterial agent(s) in $C$. aromaticum.

Traditional medicinal practice has been known for centuries in many parts of the world for the treatment of various human ailments. The use of antibiotics has revolutionized the treatment of bacterial infections; however, the misuse of antibiotics could lead to the emergence of resistant forms of bacteria. These drug-resistant microorganisms pose a greater threat to the public health. ${ }^{1,2} \mathrm{~A}$ feasible way to combat the problem of

Correspondence to: A.K.M. Mahbub Hasan

E-mail: hnmahbub@yahoo.com

Dhaka Univ. J. Pharm. Sci. 13(2): 221-224, 2014 (December) microbial resistance is the development of new antibacterial agents for substitution of less effective ones. ${ }^{3}$ Thus, attention has been shifted globally towards finding new chemicals, specifically from herbal origin, for the development of new drugs. ${ }^{4}$ The study indicated that natural products are important sources for new drugs and are also good lead compounds suitable for further modification for drug development. Numerous methods have been utilized to acquire compounds for drug discovery, including isolation from plants and other natural sources ${ }^{5}$, synthesis $^{6}$, combinatorial chemistry and molecular modeling. ${ }^{1,7,8} \mathrm{~A}$ number of medicinal plants have been investigated for their antibacterial potential. ${ }^{1,9-11}$ Owing to various ethnopharmacological properties of Cinnamomun aromaticum, the present investigation was undertaken to evaluate the antibacterial potential of its stem bark extract against a range of food-borne pathogenic bacteria.

The stem bark of $C$. aromaticum find out botanical authority (Family- Lauraceae) was collected from the garden of Sugarcane Research Institute, Pabna, Bangladesh in June, 2012 (Memo no-2523). The plant was identified by Mr. A N M Rubaiyath Bin Rahman, Associate Professor, Department of Biotechnology and Genetic Engineering, Islamic University, Kushtia. There are about 250 synonyms of the scientific name of this plant and among them the most popular is $C$. zeylanicum botanical authority and C. verum J. Presl. The name of this plant in Bengali is daruchini and in 
English is cinnamon. Ten gram of stem bark was separated, washed with water, air dried, crushed and extracted sequentially with $100 \mathrm{~mL}$ organic solvent (viz.; chloroform, ethyl acetate and methanol). The extract thus obtained was filtered through a cotton plug and then re-filtered by passing through Whatman filter paper number 1 . The filtrate was then dried by complete evaporation of solvent at room temperature until a gummy mass was obtained. Stock solutions of crude extracts were prepared by dissolving appropriate amount of dried extract in a measured volume of suitable solvent to obtain a final concentration of $100 \mathrm{mg} / \mathrm{mL}$. For evaluating the antibacterial potency, $B$. subtilis ISO-3026, $K$. pneumoniae ATCC-1003, E. coli ISO-3007, X. campestris IAM-1671, and S. lutea ISO-3232 were collected from the Microbial Type Culture Collection (MTCC), ICDDR,B (International Center for Diarrhoeal Disease Research, Bangladesh). All microorganisms were grown in Mueller Hinton (MH) broth at $37^{\circ} \mathrm{C}$ for 24 hours. Each strain was then plated on $\mathrm{MH}$ agar to obtain isolated colonies, which were then used to make larger volume of cultures in $\mathrm{MH}$ medium and microbial population was confirmed to be within in $10^{6}$ to $10^{8} \mathrm{~m} / \mathrm{l}$. The cultures were harvested with cryopreservation broth. A portion of each was kept in a cryovial at $-70^{\circ} \mathrm{C}$, while the other portion was used to prepare a suspension with $25 \%$ transmittance at $600 \mathrm{~nm}$ for in vitro assays. Agar diffusion method was used for the antibacterial assay. ${ }^{12}$ Extracts were first sterilized by sterile membrane syringe filter (pore size $0.45 \mu \mathrm{m}$, Pall Life Sciences, Washington, USA). In the disc diffusion method, nutrient agar (HiMedia, India) was used as culture medium and the discs were placed aseptically over the bacterial culture on nutrient agar plates and incubated at $37^{\circ} \mathrm{C}$ for 24 hours. The diameter of zone of inhibition (mean of three replicates) that was indicated by clear area (devoid of growth of microbes) was measured to determine the antibacterial activity. Sterile blank paper discs impregnated with only respective solvent were served

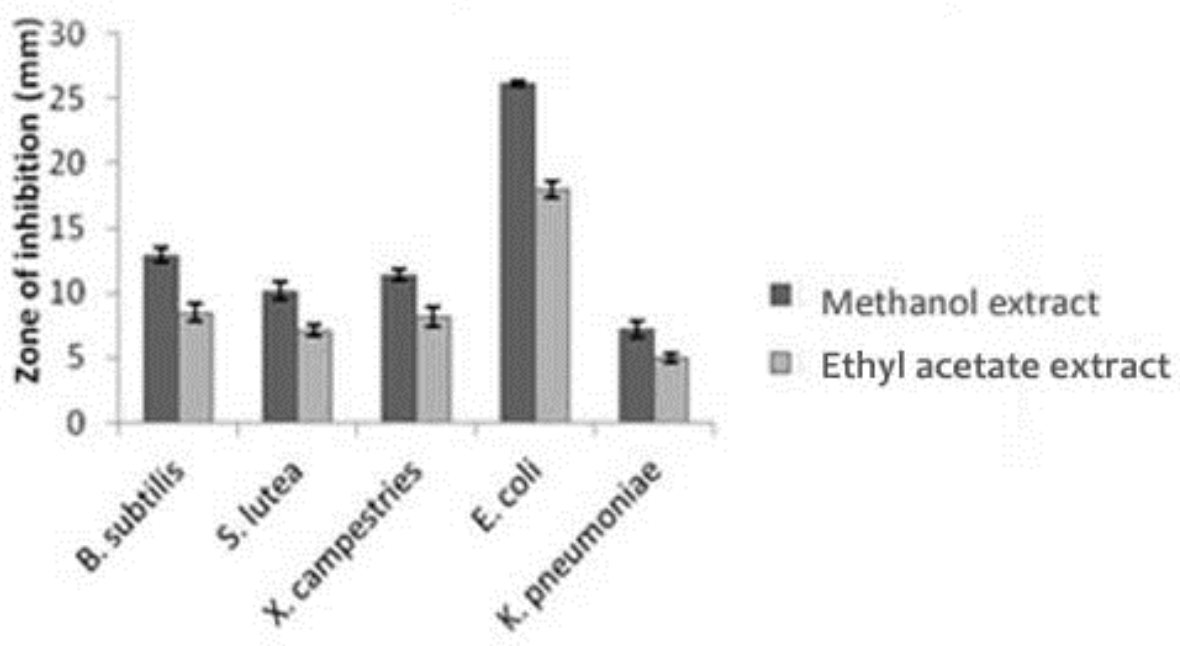

Figure 1. Zone of inhibition caused by methanol and ethyl acetate extracts of stem bark of C. aromaticum against some bacterial species.

as negative controls. Standards of nalidixic acid (30 $\mu \mathrm{g} / \mathrm{disc}$ ), oxacillin (1 $\mu \mathrm{g} / \mathrm{disc})$, penicillin $\mathrm{G}$ (10 $\mu \mathrm{g} / \mathrm{disc})$ and rifampin $(5 \mu \mathrm{g} / \mathrm{disc})$ were used as positive controls for comparison of the antibacterial activity. ${ }^{13}$ The minimum inhibitory concentrations
(MIC) of the effective plant extract was determined by serial dilution technique in which crude extracts were diluted 10 times up to the concentration of 2 $\mu \mathrm{g} / \mathrm{ml}$. Each experiment was performed three times. 
Almost all the extracts showed variable degree of inhibitory zones against different bacterial species except chloroform extract which was found to be completely inactive (data not shown). Some standard antibiotics failed to inhibit bacterial growth, for example oxacillin to $E$. coli and $K$. pneumonia (data not shown), whereas methanol and ethyl acetate extracts demonstrated significant inhibition to both bacteria. Methanol extract was found comparatively more effective with zone sizes ranging from $7 \mathrm{~mm}$ to $26 \mathrm{~mm}$. The inhibition zone caused by methanol extract was lower than that of ethyl acetate extract (Figure 1). To calculate the minimum inhibitory concentrations (MICs) of $C$. aromaticum extract in methanol, various concentrations starting from 4096 $\mu \mathrm{gmL}^{-1}$ were employed (Tables 1 and 2).

Table 1. Minimum inhibitory concentration (MIC) of methanol extract of stem bark of C. aromaticum .

\begin{tabular}{|c|c|c|c|c|c|c|c|c|c|c|c|c|c|}
\hline \multirow[t]{2}{*}{ Microorganisms } & \multicolumn{13}{|c|}{ Methanol extract of $C$. aromaticum $\left(\mu \mathrm{gmL}^{-1}\right)$} \\
\hline & 4096 & 2048 & 1024 & 512 & 256 & 128 & 64 & 32 & 16 & 8 & 4 & 2 & 0 \\
\hline Bacillus subtilis & - & - & - & + & + & + & + & + & + & + & + & + & + \\
\hline Sarcina lutea & - & - & + & + & + & + & + & + & + & + & + & + & + \\
\hline Xanthomonas campestris & - & + & + & + & + & + & + & + & + & + & + & + & + \\
\hline Escherichia coli & - & - & - & - & + & + & + & + & + & + & + & + & + \\
\hline Klebsiella pпеитопiа & - & - & - & + & + & + & + & + & + & + & + & + & + \\
\hline
\end{tabular}

'+'= Growth of bacteria; '-’= No growth

Table 2. Minimum inhibitory concentration (MIC) of ethyl acetate extract of stem bark of $C$. aromaticum .

\begin{tabular}{|c|c|c|c|c|c|c|c|c|c|c|c|c|c|}
\hline \multirow[t]{2}{*}{ Microorganisms } & \multicolumn{13}{|c|}{ Ethyl acetate extract of $C$. aromaticum $\left(\mu \mathrm{gmL}^{-1}\right)$} \\
\hline & 4096 & 2048 & 1024 & 512 & 256 & 128 & 64 & 32 & 16 & 8 & 4 & 2 & 0 \\
\hline B. subtilis & - & + & + & + & + & + & + & + & + & + & + & + & + \\
\hline S. lutea & - & + & + & + & + & + & + & + & + & + & + & + & + \\
\hline X. campestris & - & + & + & + & + & + & + & + & + & + & + & + & + \\
\hline E. coli & - & - & + & + & + & + & + & + & + & + & + & + & + \\
\hline K. pneumonia & - & + & + & + & + & + & + & + & + & + & + & + & + \\
\hline
\end{tabular}

The results of the present study clearly demonstrated that $C$. aromaticum stem-bark extracts showed significant antibacterial activity against several bacteria tested in this study. The essential oil from the bark of $C$. zeylanicum has been reported to exhibit in vitro antimicrobial activity against $P$. aeruginosa $(33.3 \mathrm{~mm})$, B. subtilis $(29.9 \mathrm{~mm}), P$. vulgaris $(29.4 \mathrm{~mm})$, K. pneumoniae $(27.5 \mathrm{~mm})$ and $S$. aureus $(20.8 \mathrm{~mm}){ }^{14}$ The ethyl acetate and acetone extracts showed no antibacterial activity against one or more bacterial strains. ${ }^{15}$ Gram-negative bacteria were found to have more susceptibility as compared to Gram-positive bacterial species. The minimum concentration to inhibit the bacterial growth was higher for ethyl acetate extract $\left(2048 \mu \mathrm{gmL}^{-1}\right)$ as compared to methanol extract $\left(512 \mu \mathrm{gmL}^{-1}\right)$. The current study supports the traditional uses of medicinal plants and suggests that some of the bark extracts possess compounds with good antimicrobial activity which can be used against certain pathogens. Further studies are needed to isolate and characterize the biocative compound(s). 


\section{ACKNOWLEDGEMENT}

We are grateful to the authority of Sugarcane Research Institute, Pabna, Bangladesh for providing the sample.

\section{REFERENCES}

1. Kaushik, P. and Goyal, P. 2008. In vitro evaluation of Datura innoxia (thorn-apple) for potential antibacterial activity. Indian J. Microbiol. 48, 353-357.

2. Russell, A.D. 2002. Antibiotic and biocide resistance in bacteria: comments and conclusions. Symp. Ser. Soc. Appl. Microbiol. 171S-173S

3. Leggiadro, R.J. 1995. Emerging drug-resistant bacteria: the wake-up call has come. South Med. J. 88, 884-886.

4. Paddon, C.J., Westfall, P.J., Pitera, D.J., Benjamin, K., Fisher, K., McPhee, D., Leavell, M.D., Tai, A., Main, A. and Eng, D. 2013. High-level semi-synthetic production of the potent antimalarial artemisinin. Nature 496, 528-532.

5. Newman, D.J. and Cragg, G.M. 2007. Natural products as sources of new drugs over the last 25 years. J. Nat. Prod. 70, 461-477

6. Khalil, A.S. and Collins, J.J. 2010. Synthetic biology: applications come of age. Nat. Rev. Genet. 11, 367-379.

7. Geysen, H.M., Schoenen, F., Wagner, D. and Wagner, R. 2003. Combinatorial compound libraries for drug discovery: an ongoing challenge. Nat. Rev. Drug. Discov. 2, 222-230.
8. Lombardino, J.G. and Lowe, J.A. 2004. The role of the medicinal chemist in drug discovery-then and now. Nat. Rev. Drug. Discov. 3, 853-862.

9. Kaushik, P. and Chauhan, A. 2008. In vitro antibacterial activity of laboratory grown culture of Spirulina platensis. Indian J. Microbiol. 48, 348-352.

10. Kaushik, P., Goyal, P., Chauhan, A. and Chauhan, G. 2010. In vitro evaluation of antibacterial potential of dry fruit extracts of Elettaria cardamomum Maton (Chhoti Elaichi). Iranian J. Pharm. Res. 9, 287-292.

11. Goyal, P., Khanna, A., Chauhan, A., Chauhan, G. and Kaushik, P. 2008. In vitro evaluation of crude extracts of Catharanthus roseus for potential antibacterial activity. Int. J. Green Pharm. 2, 176-181.

12. Murray, P., Baron, E., Pfaller, M., Tenover, F. and Yolke, R. 1995. Manual of Clinical Microbiology, 7th Edition (Washington: ASM).

13. Silva, E., Diaz, J.A., Arias, M.J., Hernandez, A.P. and de la Torre, A. 2010. Comparative in vitro study of the antimicrobial activities of different commercial antibiotic products for intravenous administration. BMC Clin. Pharmacol. 10, 3-7.

14. Prabuseenivasan, S., Jayakumar, M. and Ignacimuthu, S. 2006. In vitro antibacterial activity of some plant essential oils. BMC Complement Altern. Med. 6, 39-42.

15. Erdogrul, O. and Ates, D.A. 2006. Determination of cadmium and copper in fish samples from Sir and Menzelet Dam Lake Kahramanmaras, Turkey. Environ. Monit. Assess. 117, 281290 